\title{
Association between high fear-avoidance beliefs about physical activity and chronic disabling low back pain in nurses in Japan
}

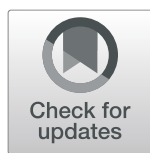

Tomoko Fujii ${ }^{*}$ (D), Hiroyuki Oka ${ }^{1}$, Kenichiro Takano², Fuminari Asada ${ }^{3}$, Takuo Nomura ${ }^{4}$, Kayo Kawamata', Hiroshi Okazaki ${ }^{5}$, Sakae Tanaka ${ }^{6}$ and Ko Matsudaira ${ }^{1}$

\begin{abstract}
Background: High prevalence of low back pain (LBP) in nurses has been reported globally. Ergonomic factors and work-related psychosocial factors have been focused on as risk factors. However, evidence on the role of fearavoidance beliefs (FABs) concerning LBP in nurses is lacking. This study examined LBP prevalence and the association between FABs and chronic disabling LBP that interfered with work and lasted $\geq 3$ months.

Methods: Female nurses ( $N=3066$; mean age $=35.8 \pm 10.6$ years) from 12 hospitals in Japan participated. A selfreported questionnaire was used to collect information on sociodemographics, LBP, work-related factors, and psychological distress. FABs about physical activity were assessed using a subscale from the FAB Questionnaire (score range $=0-24$ ). The participants were asked to choose one of four statements regarding their LBP in the past 4 weeks: 1) I did not have LBP, 2) I had LBP without work difficulty, 3) I had LBP with work difficulty but without requiring absence from work, and 4) I had LBP requiring absence from work. If the participant had LBP in the past 4 weeks, it was also inquired if the LBP had lasted for $\geq 3$ months. Chronic disabling LBP was defined as experiencing LBP with work difficulty in the past 4 weeks which had lasted for $\geq 3$ months. In the nurses who had experienced any LBP in the past 4 weeks, we examined the association between FABs and experiencing chronic disabling LBP using multiple logistic regression models adjusting for pain intensity, age, body mass index, smoking status, psychological distress, hospital department, weekly work hours, night shift work, and the12 hospitals where the participants worked.
\end{abstract}

Results: Four-week and one-year LBP prevalence were 58.7 and 75.9\%, respectively. High FABs ( $\geq 15)$ were associated with chronic disabling LBP (adjusted odds ratio $=1.76,95 \%$ confidence interval [1.21-2.57], $p=0.003$ ).

Conclusions: LBP is common among nurses in Japan. FABs about physical activity might be a potential target for LBP management in nurses.

Trial registration: UMIN-CTR UMIN000018087. Registered: June 25, 2015.

Keywords: Fear-avoidance beliefs, Low back pain, Nurses

\footnotetext{
* Correspondence: ort4771@gmail.com

'Department of Medical Research and Management for Musculoskeletal Pain,

22nd Century Medical \& Research Center, Faculty of Medicine, University of

Tokyo, 7-3-1 Hongo, Bunkyo-ku, Tokyo 113-8655, Japan

Full list of author information is available at the end of the article
}

(c) The Author(s). 2019 Open Access This article is distributed under the terms of the Creative Commons Attribution 4.0 International License (http://creativecommons.org/licenses/by/4.0/), which permits unrestricted use, distribution, and reproduction in any medium, provided you give appropriate credit to the original author(s) and the source, provide a link to the Creative Commons license, and indicate if changes were made. The Creative Commons Public Domain Dedication waiver (http://creativecommons.org/publicdomain/zero/1.0/) applies to the data made available in this article, unless otherwise stated. 


\section{Background}

Low back pain (LBP) is a common physical symptom, which approximately $80 \%$ of people experience at some point during their lifetime [1]. LBP is the leading cause of years lived with a disability globally [2]. Especially, a high prevalence of LBP among nurses has been reported worldwide. The reported one-year prevalence of LBP is $60-70 \%$ [3-7]. In Japan, LBP is the leading occupational ailment that requires sick leave $\geq 4$ days, and the number of cases is especially high in the health and hygiene industry [8], including hospitals and nursing facilities.

The etiology of LBP is multifactorial. For LBP in nurses, ergonomic factors such as patient handling and other nursing duties have been focused on primarily as risk factors [9]. Therefore, for LBP prevention, using assistive devices like lifts and sliding boards and manual handling training to reduce the physical load on nurses' backs have been recommended, although there is a lack of strong evidence of their efficacy [10].

Psychological factors such as distress, depressive mood, and depression are risk factors for new episodes of LBP [11] as well as for chronicity and disability [12]. Taiwanese and Australian studies have reported an association between psychological symptoms or psychological distress and LBP in nurses [13, 14]. Stress management has been included as an intervention for LBP control in nurses [15].

Among the psychosocial factors associated with LBP, fear-avoidance beliefs (FABs) is a cognitive factor that predicts the outcomes of patients with LBP $[12,16,17]$. In the fear-avoidance model, pain-related fear leads to avoidance behavior, resulting in disuse, depression, and disability [16]. A study reported that FABs predicted sickness absence in female healthcare helpers and assistants who had recently graduated from school [18]. However, most studies on the association between FABs and LBP outcomes have been conducted on patients with LBP or workers on sick leave [19]. There have been few reports regarding FABs and LBP disability among nurses working in hospitals [20]. If FABs play an important role in LBP disability in hospital nurses, they could be a target for LBP control along with ergonomic factors and psychological stress in this population. We collected data about LBP and related information as a baseline assessment in a randomized controlled trial (RCT) about LBP using a large sample of nurses across Japan, and examined the association between FABs and chronicity/disability of LBP.

\section{Methods}

\section{Aim, design, and setting}

The aim of this cross-sectional study was to examine 1) the four-week and one-year prevalence of LBP and 2) the association between FABs and chronic disabling LBP in nurses working in hospitals across Japan.

\section{Participants}

This study utilized baseline data from an RCT on the effects of stretching exercises on nurses' LBP, which was conducted from July 1, 2015 to June 30, 2016 [21]. The study was registered in the University Hospital Medical Information Network Clinical Trial Registry (UMIN-CTR) (ID: UMIN000018087). The study utilized the population approach with cluster randomization. The intervention was stretching exercises, which were expected to be conducted in the workplace, to promote the exercise habits of all nurses, and to prevent LBP as well as improve LBP disability. Nurses working in 12 hospitals across Japan were invited. The inclusion criteria were all nurses who were working in the 12 hospitals and agreed to participate in the RCT. The exclusion criteria were 1) unwillingness to participate and 2) being pregnant. As this RCT utilized the population approach, nurses without LBP at baseline were not excluded. The participants were asked to individually return the completed baseline questionnaire in a sealed envelope to reduce reporting bias. In these 12 hospitals, 3439 nurses consented to participate in the study and completed the baseline survey. Men were excluded from this analysis owing to their small number $(n=186)$. Additionally, 187 respondents were excluded owing to pregnancy or missing information on sex, pregnancy, or LBP in the past 4 weeks. Thus, 3066 nurses were included in this study.

The RCT was approved by the medical/ethics review boards of the 12 hospitals and Kansai University of Welfare Sciences. All participants provided written informed consent.

\section{Assessment}

Data were collected through a paper-based, selfadministered questionnaire. Demographic variables, such as age, sex, height, body weight, smoking status, and pregnancy, were collected. Body mass index (BMI) was calculated based on self-reported body weight and height: weight (kg)/height $(\mathrm{m})^{2}$. Nurses were separated into two groups: non-overweight and overweight $(\mathrm{BMI}<25$ and $\mathrm{BMI} \geq 25$, respectively) owing to the small number of nurses with a $\mathrm{BMI} \geq 30$.

Work-related data, such as those concerning hospital departments (ward, outpatient clinic, or other), work hours per week during the past month $(<40 \mathrm{~h}, 40-49 \mathrm{~h}, 50-59 \mathrm{~h}$, and $\geq 60 \mathrm{~h}$ ), years of nursing experience, night shift work, and being in a managerial position, were also collected. Categories were combined owing to low frequencies: outpatient clinics and "other" for hospital department and 50-59 and $\geq 60$ for work hours.

\section{LBP}

Participants were asked whether they had experienced LBP in the past 4 weeks using a question written by the researchers. LBP was defined as pain localized between 
the costal margin and the inferior gluteal folds lasting for $\geq 1$ day that may be accompanied by leg pain or numbness [22], but excluding pain related to menstruation, pregnancy, or the common cold. The definition of LBP and a diagram with a shaded area illustrating the area of pain were provided on the questionnaire. Participants were asked to choose one of the four statements regarding their LBP status in the past 4 weeks: 1) I did not have LBP, 2) I had LBP without work difficulty, 3) I had LBP with work difficulty but without requiring absence from work, and 4) $I$ had LBP requiring absence from work. If a nurse had LBP in the past 4 weeks, we also asked whether the LBP had lasted for $\geq 3$ months. In addition, the severity of LBP in the past 4 weeks was assessed using an 11-point numerical rating scale (NRS) $(0=n o$ pain to $10=$ the most intense pain imaginable). LBP experience in the past year was also inquired about with a question and responses similar to those mentioned above, because previous studies often reported a one-year prevalence of LBP.

\section{Chronic disabling LBP}

Nurses who answered that they had LBP with work difficulty (response 3 or 4 to the above question) in the past 4 weeks and that their LBP had lasted for $\geq 3$ months were considered to be experiencing chronic disabling LBP. Any other LBP in the past 4 weeks was classified as non-chronic disabling LBP; this included LBP without work difficulty but lasted $\geq 3$ months or LBP with work difficulty but lasted $<3$ months.

\section{FABs}

The Fear-Avoidance Beliefs Questionnaire (FABQ), developed by Waddell and colleagues, consists of 16 selfreported items with two subscales: FABs related to work and FABs related to physical activity [23]. In this study, we used a previously developed and validated Japanese version of the FABQ [24]. Although more evidence regarding the association between the work subscale and LBP work outcomes has been accumulated, we used the four-item physical activity subscale (FABQ-PA), which assesses respondents' FABs about physical activity. This was chosen because the intervention in the RCT was stretching exercises which were expected to promote nurses' exercise habits. The FABQ work subscale was not included in the questionnaire in order to reduce the burden on the participants. Responses were provided on a seven-point Likert scale ranging from 0 (completely disagree) to 6 (completely agree). Thus, total scores ranged from 0 to 24 , and higher scores represented higher levels of FABs. High FABs about physical activity were defined as scores $\geq 15$ [25].

\section{Psychological distress}

The Kessler Psychological Distress Scale (K-6), which is a short version of the original10-item scale [26], is commonly used to assess psychological distress. It measures distress over the prior 30 days using a five-point Likert scale $(0=$ none of the time to $4=$ all of the time $)$. In this study, we used a previously developed and validated Japanese version of the K-6 [27].

\section{Statistical analyses}

Initially, the four-week and one-year prevalence of LBP and other participant characteristics were examined using descriptive statistics (i.e., means and percentages). Participants were placed into three groups based on LBP status in the past 4 weeks: nurses without LBP, those who had chronic disabling LBP, and those who had LBP other than chronic disabling LBP in the previous 4 weeks (nonchronic disabling LBP). Group characteristics were compared using chi-square tests for categorical variables and Kruskal-Wallis tests for continuous variables.

The association between high FABs (FAB-PA score $\geq$ 15 ) and experiencing chronic disabling LBP in the past 4 weeks was examined using logistic regression models. Only nurses who had experienced LBP in the past 4 weeks were included in the analyses, because the FABQ asks about participants' beliefs regarding their own LBP, and the scores should have been higher in those who had LBP at the time of assessment compared with those who did not. The dependent variable was experiencing chronic disabling LBP as opposed to having non-chronic disabling LBP, and the independent variable was the FAB-PA score ( $\geq 15$ vs. $<15)$. Model 1 was a crude model. Model 2 was adjusted for NRS of LBP in the past 4 weeks. Model 3 was further adjusted for age group $(20-29,30-39,40-49$, and $\geq 50)$, BMI $(<25$ and $\geq 25)$, smoking status (non-smoker, former smoker, and current smoker), hospital department (ward and outpatient clinic/ other), weekly work hours in the past month $(<40 \mathrm{~h}, 40-$ $49 \mathrm{~h}$, and $\geq 50 \mathrm{~h}$ ), night shift work (yes or no), K-6 score $(<10,10-14$, and $\geq 15)$, and the 12 hospitals where the nurses worked. Odds ratios (ORs) and their 95\% confidence intervals (CIs) were estimated. The number of years working as a nurse was strongly correlated with age $(r>$ 0.80 ); thus, it was not included in the model. Managerial position was also not included in the final model owing to the low frequency and because the change in results was negligible after adjusting for it.

Characteristics of nurses with LBP who had missing covariable values and were excluded from logistic regression analyses were compared with those who were included using chi-square tests for categorical variables and Kruskal-Wallis tests for continuous variables.

Analyses were conducted using SAS version 9.4 (SAS Institute, Inc., Cary, NC, USA). All analyses were twosided and $p$-values $<0.05$ were considered statistically significant. 


\section{Results}

Figure 1 displays a participant flow chart. The characteristics of the 3066 nurses included in the study are shown in Table 1. The four-week and one-year prevalence of any LBP were 58.7 and $75.9 \%$, respectively. Further, 1613 (52.7\%) had non-chronic disabling and 188 (6.1\%) had chronic disabling LBP at the time of assessment. For some nurses (258 out of 1265, 20.4\%) the NRS value of LBP in the past 4 weeks was above $0($ minimum $=1$, maximum $=7$, mean $=0.5$, standard deviation $(\mathrm{SD})=$ 1.0 ), even though they answered that they did not have LBP during that time. For the majority of them $(n=132$, ) the NRS value was 1 , but for one nurse, the NRS value was 7 (NRS 2: $n=70$, NRS $3: n=33$, NRS $4: n=15$, NRS 5: $n=7)$. As LBP grades increased, so too did being overweight or obese, working in wards, working for $\geq 50 \mathrm{~h} /$ week, and working night shifts. The percentages of nurses with $\mathrm{K} 6$ score $\geq 10$ and FABQ-PA score $\geq 15$ increases with LBP grades.

The results of the logistic regression analysis are shown in Table 2. High FABQ-PA score $(\geq 15)$ was significantly associated with experiencing chronic disabling LBP (as opposed to having non-chronic disabling LBP) in the nurses who had any LBP during the past 4 weeks in the crude model. In Model 2, after adjusting for pain severity (NRS), the association was attenuated, but still significant. In the final multiple model further adjusting for age, BMI, smoking status, hospital departments, work hours, night shift work, K6 score, and the 12 hospitals where the nurses worked, high FABQ-PA score was still significantly associated with chronic disabling LBP (OR = 1.76 [1.21, 2.57], $p=0.003)$. All intermediate models and ORs with 95\% CIs have been depicted in Additional file 1: Table S1.

The characteristics of nurses with LBP who were excluded from logistic regression analyses owing to missing information were compared with the characteristics of those who were included. Although the nurses with LBP who were excluded from logistic regression analyses were younger (mean age $=33.4 \pm 9.8$ vs. $36.0 \pm$ 10.6 years, respectively; $p=0.001$ ) and tended to have higher NRS for LBP (mean NRS $=3.5 \pm 1.7$ vs. $3.2 \pm 1.6$,

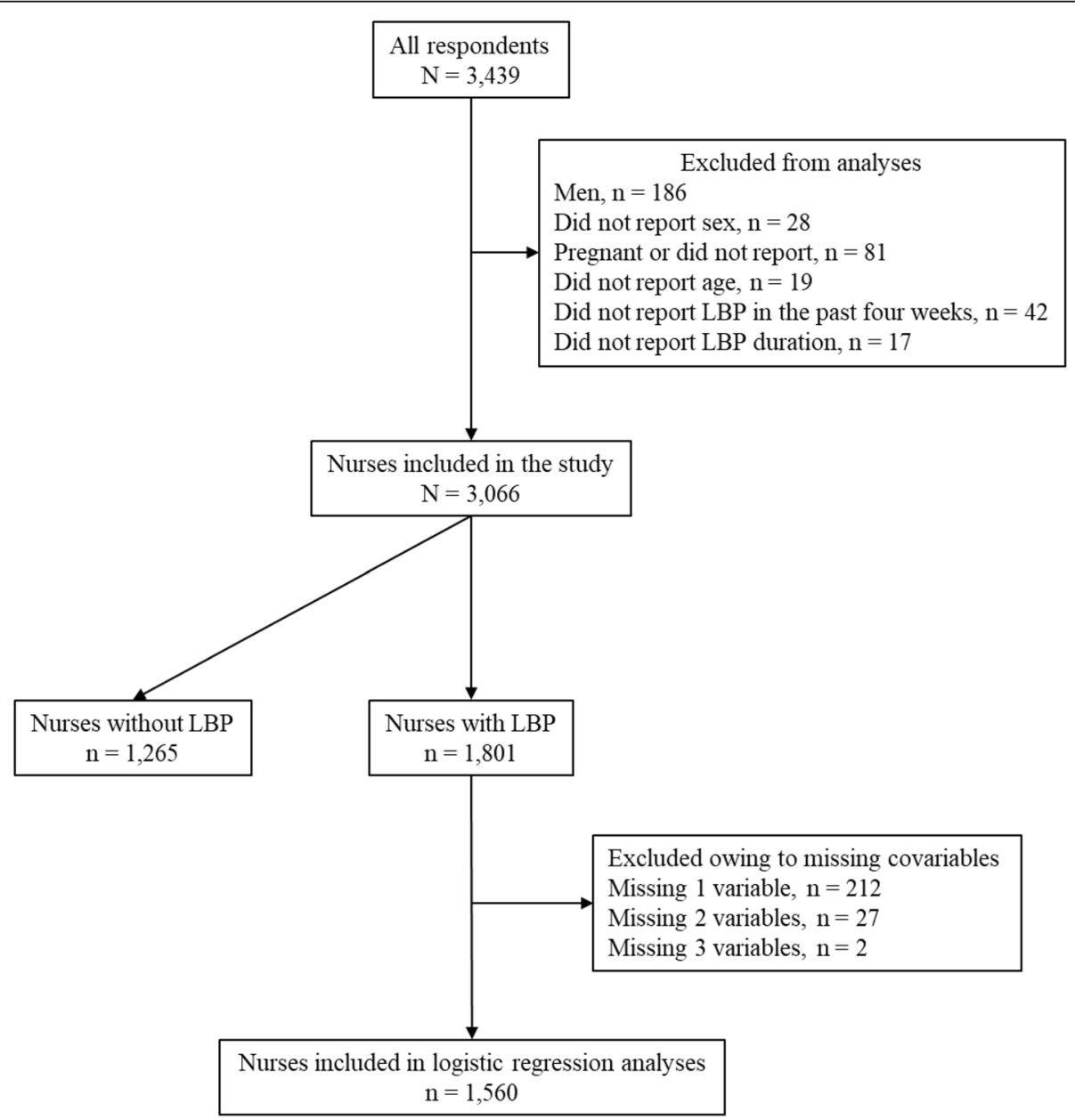

Fig. 1 Flow of the participants 
Table 1 Participants' characteristics $(N=3066)$

\begin{tabular}{|c|c|c|c|c|c|c|}
\hline & All & No LBPa & Non-chronic disabling LBP & Chronic disabling LBPC & & \\
\hline & $N=3066$ & $n=1265$ & $n=1613$ & $n=188$ & Missing (n) & $p$-value \\
\hline $\begin{array}{l}\text { Age (years), mean } \\
\text { (standard deviation) }\end{array}$ & $35.8(10.6)$ & $36.0(10.6)$ & $35.4(10.5)$ & $37.5(10.9)$ & 0 & 0.021 \\
\hline Age (\%) & & & & & 0 & 0.108 \\
\hline $20-29$ & $1114(36.3)$ & $450(35.6)$ & $606(37.6)$ & $58(30.9)$ & & \\
\hline $30-39$ & $837(27.3)$ & $335(26.5)$ & $454(28.2)$ & $48(25.5)$ & & \\
\hline $40-49$ & $733(23.9)$ & $325(25.7)$ & $356(22.1)$ & $52(27.7)$ & & \\
\hline$\geq 50$ & $382(12.5)$ & $155(12.3)$ & $197(12.2)$ & $30(16.0)$ & & \\
\hline Body mass index (\%) & & & & & 113 & $<0.001$ \\
\hline$<25$ & $2669(90.4)$ & $1148(93.1)$ & $1364(88.7)$ & $157(86.3)$ & & \\
\hline$\geq 25$ & $284(9.6)$ & $85(6.9)$ & $174(11.3)$ & $25(13.7)$ & & \\
\hline Smoking status (\%) & & & & & 37 & 0.071 \\
\hline None-smoker & $2485(82.0)$ & $1047(83.7)$ & $1298(81.4)$ & $140(76.1)$ & & \\
\hline Former & $307(10.1)$ & $121(9.7)$ & $160(10.0)$ & $26(14.1)$ & & \\
\hline Current & $237(7.8)$ & $83(6.6)$ & $136(8.5)$ & $18(9.8)$ & & \\
\hline Work experience (\%) & & & & & 11 & 0.277 \\
\hline$<1$ year & $223(7.3)$ & $88(7.0)$ & $126(7.9)$ & $9(4.8)$ & & \\
\hline$\geq 1$ to $<2$ years & $190(6.2)$ & $83(6.6)$ & $96(6.0)$ & $11(5.9)$ & & \\
\hline$\geq 2$ to $<5$ years & $482(15.8)$ & $190(15.1)$ & $268(16.7)$ & $24(12.8)$ & & \\
\hline$\geq 5$ to $<10$ years & $522(17.1)$ & $230(18.2)$ & $260(16.2)$ & $32(17.1)$ & & \\
\hline$\geq 10$ to $<20$ years & $841(27.5)$ & $334(26.5)$ & $457(28.5)$ & $50(26.7)$ & & \\
\hline$\geq 20$ years & $797(26.1)$ & $337(26.7)$ & $399(24.8)$ & $61(32.6)$ & & \\
\hline Hospital department (\%) & & & & & 86 & $<0.001$ \\
\hline Ward & $2281(76.5)$ & $896(72.7)$ & $1233(78.8)$ & $152(83.1)$ & & \\
\hline Outpatient clinic/other & $699(23.5)$ & $336(27.3)$ & $332(21.2)$ & $31(16.9)$ & & \\
\hline Work hours (per week) (\%) & & & & & 70 & $<0.001$ \\
\hline$<40$ & $455(15.2)$ & $216(17.5)$ & $219(13.9)$ & $20(10.8)$ & & \\
\hline $40-49$ & $1799(60.1)$ & $756(61.2)$ & $941(59.7)$ & $102(55.1)$ & & \\
\hline$\geq 50$ & $742(24.8)$ & $263(21.3)$ & $416(26.4)$ & $63(34.1)$ & & \\
\hline Night shift (\%) & & & & & 10 & $<0.001$ \\
\hline Yes & $2334(76.4)$ & $916(72.5)$ & $1263(78.7)$ & $155(82.5)$ & & \\
\hline No & $722(23.6)$ & $347(27.5)$ & $342(21.3)$ & $33(17.6)$ & & \\
\hline Managerial position (\%) & & & & & 4 & 0.019 \\
\hline Yes & $228(7.5)$ & $106(8.4)$ & $117(7.3)$ & $5(2.7)$ & & \\
\hline No & $2834(92.6)$ & 1157 (91.6) & $1494(92.7)$ & $183(97.3)$ & & \\
\hline K6 (\%) & & & & & 49 & $<0.001$ \\
\hline $0-4$ & 2106 (69.8) & 961 (77.5) & $1053(66.1)$ & $92(50.3)$ & & \\
\hline $5-9$ & $619(20.5)$ & $192(15.5)$ & $373(23.4)$ & $54(29.5)$ & & \\
\hline$\geq 10$ & $292(9.7)$ & $87(7.0)$ & $168(10.5)$ & $37(20.2)$ & & \\
\hline FABQ-PA (\%) & & & & & 38 & $<0.001$ \\
\hline$<15$ & $2143(70.8)$ & 1041 (83.4) & $1031(64.7)$ & $71(38.2)$ & & \\
\hline$\geq 15$ & 885 (29.2) & 207 (16.6) & $563(35.3)$ & $115(61.8)$ & & \\
\hline
\end{tabular}


Table 1 Participants' characteristics $(N=3066)$ (Continued)

\begin{tabular}{|c|c|c|c|c|c|c|}
\hline & \multirow{2}{*}{$\begin{array}{l}\text { All } \\
N=3066\end{array}$} & \multirow{2}{*}{$\begin{array}{l}\text { No LBPa } \\
n=1265\end{array}$} & \multirow{2}{*}{$\begin{array}{l}\text { Non-chronic disabling LBP } \\
n=1613\end{array}$} & \multirow{2}{*}{$\begin{array}{l}\text { Chronic disabling LBPC } \\
n=188\end{array}$} & \multirow[b]{2}{*}{ Missing (n) } & \multirow[b]{2}{*}{$p$-value } \\
\hline & & & & & & \\
\hline LBP in 4 weeks (\%) & & & & & & NA \\
\hline No LBP & $1265(41.3)$ & $1265(100)$ & $0(0)$ & $0(0)$ & & \\
\hline LBP without work difficulty & $1580(51.5)$ & $0(0)$ & $1580(98.0)$ & $0(0)$ & & \\
\hline $\begin{array}{l}\text { LBP with work difficulty but } \\
\text { without sick leave }\end{array}$ & $216(7.1)$ & $0(0)$ & $30(1.9)$ & $186(98.9)$ & & \\
\hline LBP with sick leave & $5(0.2)$ & $0(0)$ & $3(0.2)$ & $2(1.1)$ & & \\
\hline LBP NRS in 4 weeks, mean (SD) & $2.2(2.0)$ & $0.5(1.0)$ & $3.1(1.5)$ & $5.1(1.7)$ & 252 & $<0.001$ \\
\hline LBP in 1 year (\%) & & & & & 7 & $<0.001$ \\
\hline No LBP & $737(24.1)$ & $703(55.7)$ & $32(2.0)$ & $2(1.1)$ & & \\
\hline LBP without work difficulty & $1678(54.9)$ & $492(39.0)$ & $1179(73.3)$ & $7(3.7)$ & & \\
\hline $\begin{array}{l}\text { LBP with work difficulty but } \\
\text { without sick leave }\end{array}$ & $596(19.5)$ & $62(4.9)$ & $371(23.1)$ & $163(86.7)$ & & \\
\hline LBP with sick leave & $48(1.6)$ & $6(0.5)$ & $26(1.6)$ & $16(8.5)$ & & \\
\hline
\end{tabular}

LBP low back pain, K6 Kessler Psychological Distress Scale, FABQ-PA Fear-Avoidance Beliefs Questionnaire physical activity subscale, NRS numerical rating scale, NA not applicable

${ }^{a}$ No LBP: Not experiencing LBP in the past 4 weeks

${ }^{b}$ Non-chronic LBP: any LBP in the past 4 weeks other than chronic disabling LBP

'Chronic disabling LBP: Experiencing LBP in the past 4 weeks that interfered with work and had lasted for $\geq 3$ months

Table 2 Association between chronic disabling LBP and fear-avoidance beliefs in nurses with LBP in 4 weeks

\begin{tabular}{|c|c|c|c|c|c|c|c|}
\hline & \multicolumn{2}{|l|}{ Model 1} & \multicolumn{2}{|l|}{ Model 2} & \multicolumn{3}{|l|}{ Model 3} \\
\hline & OR [95\% Cl] & $p$-value & OR $[95 \% \mathrm{Cl}]$ & $p$-value & OR $[95 \% \mathrm{Cl}]$ & $p$-value & Type $3 p$-value \\
\hline FABQ-PA $\geq 15$ vs. $<15$ & $3.19[2.28,4.46]$ & $<0.001$ & $1.95[1.35,2.82]$ & $<0.001$ & $1.76[1.21,2.57]$ & 0.003 & 0.003 \\
\hline LBP NRS per 1 point & & & $1.91[1.72,2.12]$ & $<0.001$ & $1.88[1.69,2.10]$ & $<0.001$ & $<0.001$ \\
\hline Age & & & & & & & 0.122 \\
\hline $20-29$ & & & & & 1 & & \\
\hline $30-39$ & & & & & $1.09[0.66,1.80]$ & 0.748 & \\
\hline $40-49$ & & & & & $1.72[1.03,2.89]$ & 0.039 & \\
\hline$\geq 50$ & & & & & $1.67[0.89,3.12]$ & 0.110 & \\
\hline Overweight, yes vs. no & & & & & $0.92[0.53,1.61]$ & 0.774 & 0.774 \\
\hline Smoking status & & & & & & & 0.223 \\
\hline None-smoker & & & & & 1 & & \\
\hline Former & & & & & $1.56[0.92,2.66]$ & 0.101 & \\
\hline Current & & & & & $1.30[0.68,2.46]$ & 0.428 & \\
\hline Clinic or other vs. ward & & & & & $0.61[0.34,1.10]$ & 0.101 & 0.101 \\
\hline Work hours (per week) & & & & & & & 0.946 \\
\hline$<40$ & & & & & $1.06[0.57,1.95]$ & 0.854 & \\
\hline $40-49$ & & & & & 1 & & \\
\hline$\geq 50$ & & & & & $1.07[0.71,1.61]$ & 0.755 & \\
\hline Night shift, yes vs. no & & & & & $1.20[0.67,2.13]$ & 0.548 & 0.548 \\
\hline K6 & & & & & & & 0.267 \\
\hline $0-4$ & & & & & 1 & & \\
\hline $5-9$ & & & & & $1.19[0.77,1.83]$ & 0.436 & \\
\hline$\geq 10$ & & & & & $1.53[0.91,2.58]$ & 0.109 & \\
\hline
\end{tabular}

Chronic disabling LBP: Experiencing LBP in the past 4 weeks that interfered with work and had lasted for $\geq 3$ months

Model 3: All variables and the 12 hospitals were mutually adjusted

$O R$ odds ratio, $C l$ confidence interval, $F A B Q-P A$ Fear-Avoidance Beliefs Questionnaire physical activity subscale, LBP low back pain, NRS numerical rating scale, $K 6$ Kessler Psychological Distress Scale 
respectively; $p=0.05)$ compared with those who were included in the logistic models, there were no significant differences in the percentage of chronic disabling LBP, FABQ-PA scores, K6 scores, or other covariables.

In the sensitivity analysis, nurses who answered that they did not have LBP in the past 4 weeks but gave an LBP NRS value above 0 were re-classified as the "nonchronic disabling LBP" group. The estimate of the association between FABs and chronic disabling LBP did not essentially change (Additional file 2: Table S2). Similarly, when nurses who answered that they did not have LBP in the past 4 weeks but also responded that their current LBP had lasted for $\geq 3$ months $(n=120,9.5 \%)$ were reclassified as the non-chronic disabling LBP group, the results did not essentially change (Additional file 3: Table S3).

\section{Discussion}

This study found that LBP was common in nurses based on a relatively large sample of female nurses working in 12 hospitals across Japan. The results also suggest that FABs might play an important role in the chronicity and disability of LBP in this group of women.

Our results are comparable to the reported one-month LBP prevalence of $54.7 \%$ among nurses working in a national university hospital in the western prefecture of Japan [28]; however, a more recent study reported a one-month LBP prevalence of $30 \%$ among nurses in a university hospital in Tokyo [29]. Smith and colleagues reported a one-year prevalence of $59 \%$, ranging from 50 to $71 \%$ depending on the hospital department; specifically, they examined 305 nurses working in a rural Japanese university hospital [3]. In sum, the prevalence of LBP in our study was somewhat higher compared with these previous studies. We inquired about participants' LBP status using the definition along with a diagram which was recommended as a standardized definition by Dionne et al. [22]. Despite variations in study populations, and LBP definitions, our results showed that LBP is still as common in nurses working in hospitals in Japan as in other countries [4-7].

Nonetheless, sick leave because of LBP was not common. Consistent with our results, a previous study showed that the rate of sick leave owing to musculoskeletal pain was 3\% in Japanese nurses and that such sick leave was less common in Japanese workers compared with workers from the UK [29]. Another study reported that health-related costs associated with presenteeism (reduced performance while at work) were much higher than medical/pharmaceutical expenses or productivity loss associated with sick leave (absenteeism), and that LBP was the third leading cause of presenteeism following neck pain/stiff shoulders and insufficient sleep in Japanese pharmaceutical workers [30]. Although only 6\% had chronic disabling LBP at the time of assessment, $21 \%$ of our participants answered that they had LBP that interfered with work sometime in the past year. Presenteeism among these nurses should not be ignored, because the shortage of nurses and their severe working conditions are significant problems in Japan. Efforts should be made to prevent and alleviate nurses' LBP.

In nurses with LBP, those with high FABs about physical activity were about 1.8 times more likely to have chronic disabling LBP, even after adjusting for pain severity, psychological distress, work hours, night shift work, and other variables, which suggests that FABs about physical activity might be critically related to nurses' LBP disability. Previously, focus was placed on physical risk factors for the occurrence of LBP, like heavy lifting or carrying, bending, awkward posture, and moving patients $[9,31]$. In addition, the importance of psychosocial factors in LBP chronicity and disability has been recognized [12]. Work-related psychosocial factors, including high job demands, low job control, effortreward imbalance, and low social support, were associated with LBP in nurses and nursing aides [32]. FABs, especially about work, have also been reported to predict LBP outcomes such as return to work [19]. Jensen and colleagues reported that high FABs about work were associated with sick leave days a year later and were an effect modifier between LBP severity and sick leave days in healthcare assistants and helpers who recently graduated in Denmark [18]. In their cross-sectional study of 203 hospital employees in Japan, after adjusting for various work-related psychosocial factors, Yoshimoto and colleagues reported that high FABs about physical activity were associated with having LBP that interfered with work [33]. Further, high FAB-PA scores were associated with higher LBP disability, which was assessed using the Roland-Morris Disability Questionnaire (RDQ) in Chinese and Australian nurses in a cross-sectional study by Tan et al. [20]. A systematic review also showed that FABs about work predict work-related outcomes in subacute LBP. Our results were consistent with those studies. Although there is a lack of evidence regarding whether FABs about physical activity predict work-related LBP outcomes, this and previous studies suggest that FABs about physical activity are associated with work disability among nurses, as are other psychosocial factors. Nurses are required to complete physical tasks such as handling patients, which might be a reason why FABs about physical activity were associated with work-related outcomes in our study.

For LBP control in nurses, interventions addressing ergonomic and psychosocial factors have been conducted [10, 15]. However, a Cochrane review reported no evidence on the preventative effect of manual handling training or assistive device provisions [10]. A systematic 
review by Van Hoof and colleagues concluded that there was no strong evidence for the efficacy of varied interventions, including manual handling training, stress management, stretching exercises, and "back school" for LBP prevention and treatment [15]. Another systematic review by Roffey and colleagues did not find evidence of a causal association between assisting patients and LBP [34], which might partially explain the scant evidence regarding the efficacy of manual handling training for LBP prevention. The results of our study suggest that FABs about physical activity might be another target for LBP control. In their pilot study, Monnin and colleagues reported that FABQ physical scores and work scores decreased significantly and remained at a six-month follow-up in healthcare workers who completed a 10-h educational program using the Back Book over 2 days, as compared with a control program [35]. Although their study did not report LBP outcomes, the intervention addressing FABs could be beneficial for the management of LBP in nurses.

One of the strengths of this study was its large sample size. Participants were nurses working in 12 hospitals across Japan. Thus, the results likely reflect the true prevalence of LBP in nurses in Japan. We collected relevant information including work hours, night shift work, and psychological distress, which are likely related to LBP. However, this study had a few limitations. Ergonomic factors regarding nursing tasks such as the frequency of patient lifting and use of assistive devices were not considered. We assessed LBP using one question with four possible responses, and LBP status was determined based on retrospective self-reports. Recall for LBP in the past year may not be accurate [36]. In addition, the nurses who expressed interest and participated in the RCT regarding LBP intervention may have overstated their LBP disability or FABs about LBP, which could also lead to bias away from the null. We were not able to exclude specific LBP, such as LBP with red flags. However, the prevalence of serious pathologies was reported to be less than $1 \%$ in patients with LBP in primary care settings [37]. In addition, the participants in our study were hospital nurses who were working at the time of assessment. Thus, not excluding LBP with red flags would not have had a large impact on our results. We did not use disability questionnaires with continuous scores, such as the RDQ or Oswestry Disability Index, to reduce the burden on the busy participants, which is also a limitation. Further, because of the cross-sectional design, the causal relationship between FABs and LBP remains unknown. Higher FABs could be a consequence of chronic disabling LBP. Future prospective studies are warranted to examine the causal relationship between FABs about physical activity and work disability among nurses with LBP. In addition, non-negligible numbers of participants were excluded from logistic regression analyses owing to missing covariable values, which might have had some influence on the results. However, most characteristics of excluded participants did not significantly differ from those who were included in analyses. Finally, as the participants were nurses working in hospitals in Japan, the results may not be generalizable to nurses in other countries, although Tan et al. found that the associations between FABs and LBP disability were similar between China and Australia [20].

\section{Conclusions}

The prevalence of LBP remains high among Japanese female nurses. A small number of nurses had chronic disabling LBP that interfered with their work. In the nurses who had any type of LBP, high FABs were significantly associated with experiencing chronic disabling LBP. Targeting FABs about physical activity could be beneficial for LBP management in nurses.

\section{Supplementary information}

Supplementary information accompanies this paper at https://doi.org/10. 1186/s12891-019-2965-6.

Additional file 1: Table S1. Association between chronic disabling LBP and fear-avoidance beliefs in nurses with LBP in 4 weeks.

Additional file 2: Table S2. Results of the first sensitivity analysis.

Additional file 3: Table S3. Results of the second sensitivity analysis.

\begin{abstract}
Abbreviations
BMI: Body mass index; Cl: Confidence interval; FABQ: Fear-Avoidance Beliefs Questionnaire; FABQ-PA: Fear-Avoidance Beliefs Questionnaire-physical activity subscale; FABs: Fear-avoidance beliefs; K-6: Kessler Psychological Distress Scale; LBP: Low back pain; NRS: Numerical rating scale; OR: Odds ratio; $\mathrm{RCT}$ : Randomized controlled trial
\end{abstract}

\section{Acknowledgments}

We thank Editage for providing editorial assistance.

\section{Authors' contributions}

KM conceived and planned the study. TF analyzed and interpreted the data and drafted the manuscript. $\mathrm{HO}, \mathrm{KT}, \mathrm{FA}, \mathrm{TN}, \mathrm{KK}, \mathrm{HO}$, and ST contributed to designing the study and data acquisition. All authors read and approved the final manuscript.

\section{Funding}

This study was supported by a grant from the Ministry of Health, Labour and Welfare, Japan (no. H30-Rodo-Ippan-002). The funder had no role in the study design, data collection and analysis, decision to publish, or preparation of the manuscript.

\section{Availability of data and materials}

All datasets have ethical or legal restrictions for public deposition owing to the inclusion of sensitive information from the human participants. Anonymized data are only available upon approval by the concerned institutional medical/ethics review boards.

\section{Ethics approval and consent to participate}

All participants provided written informed consent, and this study was approved by the medical/ethics review boards of Asahi, Chugoku, Ehime, Hamamatsu, Hokkaido Chuo, Kansai, Kanto, Nagasaki, Niigata, Osaka, Tohoku, and Yokohama Rosai Hospitals, and Kansai University of Welfare Sciences. 


\section{Consent for publication}

Not applicable.

\section{Competing interests}

All authors declare the following potential conflicts of interest: KM is a shareholder and adviser of Trunk Solution CO., Ltd. KM received the following support: a research grant from the Ministry of Health, Labour and Welfare for the submitted work; grant support, including an endowed chair from Sumitomo Dainippon Pharma Co., Ltd. and Okamura Corporation; grant support, including an endowed chair and lecture fees from AYUMI Pharmaceutical Corporation, Nippon Zoki Pharmaceutical Co., Ltd., Ono Pharmaceutical Co., LTD., Eli Lilly Japan K.K., Astellas Pharma Inc., TOTO LTD. and Eisai Co., Ltd.; lecture fees from Pfizer Japan Inc., Hisamitsu Pharmaceutical Co., Inc., Janssen Pharmaceutical K.K., Kaken Pharmaceutical Co., LTD., and Teijin Pharma Limited; and lecture fees and advisory fees from Shionogi \& Co., Ltd. MTG Co., Ltd., Sompo Holdings, Inc., NUVASIVE Japan, Murata Manufacturing Co., Ltd. outside the submitted work. HO received grants from Teijin Pharma Limited, Pfizer Inc., and Fujifilm Medical Co., Ltd.; grants and personal fees from AYUMI Pharmaceutical Corporation, Nippon Zoki Pharmaceutical Co., Ltd., Ono Pharmaceutical Co., LTD. MTG Co., Ltd., Sompo Holdings, Inc., and NUVASIVE Japan; and grants from Eli Lilly Japan K.K. outside the submitted work. ST received personal fees for expert testimony from Amgen Inc., Asahi Kasei Pharma Corporation, Amgen Astellas BioPharma K.K., Ono Pharmaceutical Co., LTD., Kyocera Medical Corporation, Daiichi Sankyo Company, Limited, Teijin Pharma Limited, Eli Lilly Japan K.K., and Pfizer Japan Inc.; endowments from Astellas Pharma Inc., AYUMI Pharmaceutical Corporation, Pfizer Japan Inc., Bristol-Myers Squibb, Daiichi Sankyo Company, Limited, and Chugai Pharmaceutical Co., Ltd.; and grants from the Japan Agency for Medical Research and Development, the Japan Society for the Promotion of Science (JSPS)/Grant-in-aid for Scientific Research (A), and the JSPS/Grant-in-aid for Exploratory Research outside the submitted work. TF reports grants from Murata Manufacturing Co., Ltd. outside the submitted work. KT, FA, TN, KK, and $\mathrm{HO}$ have no competing interests to report.

\section{Author details}

'Department of Medical Research and Management for Musculoskeletal Pain, 22nd Century Medical \& Research Center, Faculty of Medicine, University of Tokyo, 7-3-1 Hongo, Bunkyo-ku, Tokyo 113-8655, Japan. ${ }^{2}$ Research Center for the Health Promotion and Employment Support, Kansai Rosai Hospital, Amagasaki, Hyogo, Japan. ${ }^{3}$ Research Center for the Health Promotion and Employment Support, Osaka Rosai Hospital, Osaka, Japan. ${ }^{4}$ Department of Rehabilitation Sciences, Kansai University of Welfare Sciences, Osaka, Japan. ${ }^{5}$ Department of Orthopaedic Surgery, Kanto Rosai Hospital, Kawasaki, Kanagawa, Japan. ${ }^{6}$ Department of Orthopaedic Surgery, Faculty of Medicine, University of Tokyo, Tokyo, Japan.

\section{Received: 28 July 2019 Accepted: 22 November 2019} Published online: 28 November 2019

\section{References}

1. Walker BF, Muller R, Grant WD. Low back pain in Australian adults: prevalence and associated disability. J Manip Physiol Ther. 2004;27:238-44.

2. Vos T, Barber RM, Bell B, Bertozzi-Villa A, Biryukov S, Bolliger I, et al. Global, regional, and national incidence, prevalence, and years lived with disability for 301 acute and chronic diseases and injuries in 188 countries, 1990-2013: a systematic analysis for the global burden of disease study 2013. Lancet. 2015;386:743-800.

3. Smith DR, Ohmura K, Yamagata Z, Minai J. Musculoskeletal disorders among female nurses in a rural Japanese hospital. Nurs Health Sci. 2003;5:185-8.

4. Dawson AP, Schluter PJ, Hodges PW, Stewart S, Turner C. Fear of movement, passive coping, manual handling, and severe or radiating pain increase the likelihood of sick leave due to low back pain. Pain. 2011;152:1517-24.

5. Sharma S, Shrestha N, Jensen MP. Pain-related factors associated with lost work days in nurses with low back pain: a cross-sectional study. Scand J Pain. 2016;11:36-41.

6. Azizpour Y, Delpisheh A, Montazeri Z, Sayehmiri K. Prevalence of low back pain in Iranian nurses: a systematic review and meta-analysis. BMC Nurs. 2017;16:50.
7. Samaei SE, Mostafaee M, Jafarpoor H, Hosseinabadi MB. Effects of patienthandling and individual factors on the prevalence of low back pain among nursing personnel. Work. 2017;56:551-61.

8. Ministry of Health, Labour and Welfare. Survey on occupational disease outbreak status. 2019. https://www.mhlw.go.jp/bunya/roudoukijun/ anzeneisei11/h29.html. Accessed 1 Jul 2019.

9. Yassi A, Lockhart K. Work-relatedness of low back pain in nursing personnel: a systematic review. Int J Occup Environ Health. 2013;19:223-44.

10. Verbeek JH, Martimo KP, Kuijer PP, Karppinen J, Viikari-Juntura E, Takala EP. Proper manual handling techniques to prevent low back pain, a Cochrane systematic review. Work. 2012;41(Suppl 1):2299-301.

11. Pinheiro MB, Ferreira ML, Refshauge $K$, Ordonana JR, Machado GC, Prado LR, et al. Symptoms of depression and risk of new episodes of low back pain: a systematic review and meta-analysis. Arthritis Care Res. 2015;67:1591-603.

12. Pincus T, Burton AK, Vogel S, Field AP. A systematic review of psychological factors as predictors of chronicity/disability in prospective cohorts of low back pain. Spine. 2002;27:E109-20.

13. Chen MJ, Weng SS. Psychological symptoms among hospital nurses in Taiwan: a cross sectional study. BMC Womens Health. 2017;17:101.

14. Feyer AM, Herbison P, Williamson AM, de Silva I, Mandryk J, Hendrie L, et al. The role of physical and psychological factors in occupational low back pain: a prospective cohort study. Occup Environ Med. 2000;57:116-20.

15. Van Hoof W, O'Sullivan K, O'Keeffe M, Verschueren S, O'Sullivan P, Dankaerts $W$. The efficacy of interventions for low back pain in nurses: a systematic review. Int J Nurs Stud. 2018;77:222-31.

16. Vlaeyen JW, Linton SJ. Fear-avoidance and its consequences in chronic musculoskeletal pain: a state of the art. Pain. 2000;85:317-32.

17. Hilfiker R, Bachmann LM, Heitz CA, Lorenz T, Joronen H, Klipstein A. Value of predictive instruments to determine persisting restriction of function in patients with subacute non-specific low back pain. Systematic review Eur Spine J. 2007;16:1755-75.

18. Jensen JN, Karpatschof B, Labriola M, Albertsen K. Do fear-avoidance beliefs play a role on the association between low back pain and sickness absence? A prospective cohort study among female health care workers. J Occup Environ Med. 2010;52:85-90.

19. Wertli MM, Rasmussen-Barr E, Weiser S, Bachmann LM, Brunner F. The role of fear avoidance beliefs as a prognostic factor for outcome in patients with nonspecific low back pain: a systematic review. Spine J. 2014;14:816-36.e4.

20. Tan BK, Smith A, O'Sullivan P, Chen G, Burnett A. Low back pain beliefs and their relationships with low back pain-related disability in nurses working in mainland China and in Australia. J Cult Divers. 2015;22:71-81.

21. Oka H, Nomura T, Asada F, Takano K, Nitta Y, Uchima Y, et al. The effect of the "one stretch" exercise on the improvement of low back pain in Japanese nurses: a large-scale, randomized, controlled trial. Mod Rheumatol. 2019;29:861-6.

22. Dionne CE, Dunn KM, Croft PR, Nachemson AL, Buchbinder R, Walkder BF, et al. A consensus approach toward the standardization of back pain definitions for use in prevalence studies. Spine. 2008;33:95-103.

23. Waddell G, Newton M, Henderson I, Somerville D, Main CJ. A fear-avoidance beliefs questionnaire (FABQ) and the role of fear-avoidance beliefs in chronic low back pain and disability. Pain. 1993;52:157-68.

24. Matsudaira K, Kikuchi N, Murakami A, Isomura T. Psychometric properties of the Japanese version of the fear-avoidance beliefs questionnaire (FABQ). J Orthop Sci. 2014;19:26-32.

25. Werneke MW, Hart DL, George SZ, Stratford PW, Matheson JW, Reyes A. Clinical outcomes for patients classified by fear-avoidance beliefs and centralization phenomenon. Arch Phys Med Rehabil. 2009;90:768-77.

26. Kessler RC, Andrews G, Colpe LJ, Hiripi E, Mroczek DK, Normand SL, et al. Short screening scales to monitor population prevalences and trends in non-specific psychological distress. Psychol Med. 2002;32:959-76.

27. Furukawa TA, Kawakami N, Saitoh M, Ono Y, Nakane Y, Nakamura Y, et al. The performance of the Japanese version of the K6 and K10 in the world mental health survey Japan. Int J Methods Psychiatr Res. 2008;17:152-8.

28. Ando S, Ono Y, Shimaoka M, Hiruta S, Hattori Y, Hori F, et al. Associations of self estimated workloads with musculoskeletal symptoms among hospital nurses. Occup Environ Med. 2000;57:211-6.

29. Matsudaira K, Palmer KT, Reading I, Hirai M, Yoshimura N, Coggon D. Prevalence and correlates of regional pain and associated disability in Japanese workers. Occup Environ Med. 2011;68:191-6.

30. Nagata T, Mori K, Ohtani M, Nagata M, Kajiki S, Fujino Y, et al. Total healthrelated costs due to absenteeism, presenteeism, and medical and 
pharmaceutical expenses in Japanese employers. J Occup Environ Med. 2018;60:e273-80.

31. Taylor JB, Goode AP, George SZ, Cook CE. Incidence and risk factors for firsttime incident low back pain: a systematic review and meta-analysis. Spine J. 2014;14:2299-319.

32. Bernal D, Campos-Serna J, Tobias A, Vargas-Prada S, Benavides FG, Serra C Work-related psychosocial risk factors and musculoskeletal disorders in hospital nurses and nursing aides: a systematic review and meta-analysis. Int J Nurs Stud. 2015;52:635-48.

33. Yoshimoto T, Oka H, Katsuhira J, Fujii T, Masuda K, Tanaka S, et al. Prognostic psychosocial factors for disabling low back pain in Japanese hospital workers. PLoS One. 2017;12:e0177908.

34. Roffey DM, Wai EK, Bishop P, Kwon BK, Dagenais S. Causal assessment o workplace manual handling or assisting patients and low back pain: results of a systematic review. Spine J. 2010:10:639-51.

35. Monnin D, Courvoisier DS, Genevay S. Modifying beliefs about back pain: a pilot study among healthcare professionals. Patient Educ Couns. 2016;99:665-70.

36. Rasmussen CDN, Holtermann A, Jorgensen MB. Recall bias in low back pain among workers: effects of recall period and individual and work-related factors. Spine. 2018:43:E727-33.

37. Henschke N, Maher CG, Refshauge KM, Herbert RD, Cumming RG, Bleasel J, et al. Prevalence of and screening for serious spinal pathology in patients presenting to primary care settings with acute low back pain. Arthritis Rheum. 2009;60:3072-80.

\section{Publisher's Note}

Springer Nature remains neutral with regard to jurisdictional claims in published maps and institutional affiliations.

Ready to submit your research? Choose BMC and benefit from:

- fast, convenient online submission

- thorough peer review by experienced researchers in your field

- rapid publication on acceptance

- support for research data, including large and complex data types

- gold Open Access which fosters wider collaboration and increased citations

- maximum visibility for your research: over $100 \mathrm{M}$ website views per year

At $\mathrm{BMC}$, research is always in progress.

Learn more biomedcentral.com/submissions 